\title{
Comparisons of Measured Rate Constants with Spectroscopically Determined Electron-Transfer Parameters ${ }^{\dagger}$
}

\author{
Stephen F. Nelsen,* Asgeir E. Konradsson, and Michael N. Weaver \\ Department of Chemistry, University of Wisconsin, 1101 University Avenue, Madison, Wisconsin 53706-1396 \\ Rachel M. Stephenson, Jenny V. Lockard, and Jeffrey I. Zink* \\ Department of Chemistry and Biochemistry, University of California, Los Angeles, California 90095
}

\author{
Yi Zhao* \\ Department of Chemical Physics, University of Science and Technology of China, Hefei 230026, \\ People's Republic of China \\ Received: December 29, 2006; In Final Form: February 13, 2007
}

\begin{abstract}
This work involves comparison of rate constants measured for an intervalence (IV) compound with electrontransfer parameters derived from its optical absorption spectrum. The temperature-dependent rate constants for the radical cation having 3-tert-butyl-2,3-diazabicyclo[2.2.2] oct-2-yl (hydrazine) charge-bearing units attached para to a tetramethylbenzene bridge $\left(\mathbf{1}^{+}\right)$were previously measured. In this study, resonance Raman is used to calculate the magnitudes of the distortions of normal modes of vibration caused by excitation into the intervalence absorption band. These data produce a vibrational reorganization energy $\lambda_{\mathrm{v}}{ }^{\mathrm{sym}}$ of $9250 \mathrm{~cm}^{-1}$, and averaged single-mode $\omega_{\mathrm{v}}$ for use in the Golden Rule equation of $697 \mathrm{~cm}^{-1}$. Zhu-Nakamura theory has been used to calculate preexponential factors for analysis of the previously measured variable temperature optical spectra using quartic-enhanced intervalence bands to extract the total reorganization energy and the intramolecular electron-transfer rate constants for intramolecular electron transfer using electron spin resonance. In contrast to using the Golden Rule equation, separation of $\lambda$ into solvent and vibrational components is not significant for these data. The Zhu-Nakamura theory calculations produce $\ln (k / T)$ versus $1 / T$ slopes that are consistent with the experimental data for electronic couplings that are somewhat larger than the values obtained from the optical spectra using Hush's method.
\end{abstract}

\section{Introduction}

The comparison of electron-transfer rate constants measured for an intervalence (IV) compound by using electron spin resonance (ESR) methods with calculated rate constants based upon electron-transfer parameters derived from spectroscopy is the focus of this paper. IV compounds have charge-bearing units (M) connected by a bridge (B) and are at an oxidation level that would allow the charges on the $\mathrm{M}$ groups to be different. IV compounds that have their extra charge almost localized on one of the $\mathrm{M}$ groups, $\mathrm{a}^{+} \mathrm{M}-\mathrm{B}-\mathrm{M}$ charge distribution for $\mathrm{a}+1$ charged system, are called class II in Robin and Day's nomenclature. ${ }^{1}$ They are the simplest electron transfer (ET) systems ever devised, and they have remained important in ET studies since Creutz and Taube published the first designed example of an IV compound in 1969, the Creutz-Taube complex $\left(\mathrm{M}=\mathrm{Ru}\left(\mathrm{NH}_{3}\right)_{5}, \mathrm{~B}=\right.$ pyrazine (1,4-diazabenzene), charge +5$).^{2-4}$ Hush had already pointed out that the longest wavelength absorption maximum for class II intervalence compounds is the total reorganization energy $\lambda$ (assuming parabolic diabatic surfaces) and showed how to evaluate the electronic coupling $V_{\mathrm{ab}}$ from the intensity of this band (assuming that the ET distance is known). ${ }^{5,6}$ Completely organic examples of delocalized (Robin-Day class III) IV compounds have been known since the 19th century: the first radical ions ever isolated,

† Part of the special issue "Norman Sutin Festschrift". including Wurster's blue ( $N, N, N^{\prime}, N^{\prime}$-tetramethyl- $p$-phenylenediamine radical cation perchlorate), ${ }^{7}$ are examples, but organic chemists did not develop the idea that it would be useful to think about the possibility of charge localization in such systems. ${ }^{8}$ Completely organic class II intervalence compounds have also been made, starting with dinitrogen-centered ones. ${ }^{9}$ These compounds have much larger $\lambda$ values than previously studied compound types, allowing study of compounds having large enough $V_{\mathrm{ab}}$ values for their IV absorption bands to be easily measured. By tuning $\lambda$ and $V_{\mathrm{ab}}$ by changing the bridge, examples have been prepared that have intramolecular ET rate constants $k_{\text {et }}$ near the $10^{8} \mathrm{~s}^{-1}$ that corresponds to the point of maximum broadening for the nitrogen hyperfine ESR splitting, allowing accurate rate constant determination. ${ }^{10,11}$ These studies allow testing of methods for evaluating ET parameters and calculating rate constants. This work led to the rather unsatisfactory result that simple, classical Marcus theory that ignores a quantum mechanical treatment of molecular vibrations ${ }^{12,13}$ predicted the observed $k_{\text {et }}$ more accurately than more sophisticated methods that incorporated such a treatment. ${ }^{14}$ It is the goal of this work to accurately establish the proper vibrational analysis of $\mathbf{1}^{+}$, which we have argued has the most accurately determined $k_{\text {et }}$ as a function of temperature of the compounds that we have studied, ${ }^{15}$ because it has less spin density on the bridge than other cases. Resonance Raman has been used to establish the 
TABLE 1: Resonance Raman Modes Excited by Irradiation into the IV Band of $1^{+a}$

\begin{tabular}{ccrc}
\hline$\omega_{\mathrm{q}}$ & $\Delta_{\mathrm{q}}$ & $\lambda_{\mathrm{q}}$ & $\lambda_{\mathrm{q}} / \lambda_{\mathrm{v}}$ \\
\hline 435 & 2.89 & 1817 & 0.197 \\
469 & 3.50 & 2875 & 0.311 \\
506 & 2.44 & 1506 & 0.163 \\
583 & 0.95 & 263 & 0.028 \\
674 & 0.93 & 292 & 0.031 \\
748 & 1.78 & 1185 & 0.128 \\
1000 & 0.19 & 18 & 0.002 \\
1163 & 0.82 & 391 & 0.042 \\
1242 & 0.90 & 503 & 0.054 \\
1404 & 0.34 & 81 & 0.009 \\
1550 & 0.64 & 317 & 0.034
\end{tabular}

${ }^{a}$ The energies are in $\mathrm{cm}^{-1}$.

vibrations excited by irradiation into its IV band, and the experimental rate constants are compared with theory.

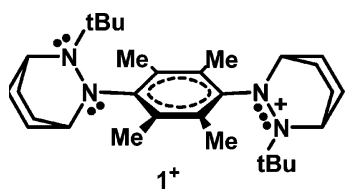

\section{Results and Discussion}

Resonance Raman Spectroscopy. Resonance Raman spectroscopy allows independent determination of both the vibrational frequencies of the modes, $\omega_{\mathrm{q}}$, that are distorted upon photoexcitation and the magnitudes of the relative distortions. Mode-specific reorganization energies $\lambda_{\mathrm{q}}$ are equal to one-half the product of the frequency and the square of the dimensionless distortion, $\Delta_{\mathrm{q}}$. These methods have been applied to many intraand intermolecular electron-transfer systems including both inorganic (transition metal complexes), ${ }^{16-30}$ and organic compounds, ${ }^{31-35}$ and heterogeneous ET reactions. ${ }^{36,37}$ Resonance Raman studies on delocalized intervalence compounds include our study on a protected tetralkylamino- $p$-phenylenediamine radical cation, ${ }^{38}$ a study of its tetraphenyl analogue, ${ }^{39}$ and studies of two diarylhydrazine radical cations. ${ }^{40,41}$

The normal modes $\omega_{\mathrm{q}}$ and their dimensionless distortions $\Delta_{\mathrm{q}}$ excited by irradiating into the IV band of $\mathbf{1}^{+}$are shown in Table 1 along with their increments contributing to the total vibrational reorganization energy $\lambda_{\mathrm{v}}=\Sigma \lambda_{\mathrm{q}}$. All of the modes that contribute $1 \%$ or more reorganization energy as that of the most important mode $\left(469 \mathrm{~cm}^{-1}\right)$ are included. Although weak Raman bands were observed in the $\mathrm{CH}$ region, much of their intensity arises from the nonresonant contributions to the scattering and have been ignored here because they are not expected to significantly contribute to ET. Each mode is fit numerically, and the intensity of the mode is the area of the fitted peak. The intensities are normalized to a standard nitrate peak at $716 \mathrm{~cm}^{-1}$ measured simultaneously with the sample. The relative $\Delta_{\mathrm{q}}$ values are calculated from the normalized intensities using eq 1

$$
\frac{I_{k}}{I_{k^{\prime}}}=\frac{\left(\Delta_{k}^{2} \omega_{k}^{2}\right)}{\left(\Delta_{k^{\prime}}^{2} \omega_{k^{\prime}}^{2}\right)}
$$

where $k$ represents a mode of $\mathbf{1}^{+}$and $k^{\prime}$ represents the standard nitrate mode (with a relative $\Delta_{k^{\prime}}$ of 1 ). ${ }^{42-50}$ Equation 1 assumes that the potential surfaces are harmonic, that there is no change in force constant between the ground and excited states, and that the Condon approximation is valid. The values of each of the individual $\Delta_{\mathrm{q}}$ values are determined from the relative $\Delta_{\mathrm{q}}$ values by fitting the optical absorption spectrum using the

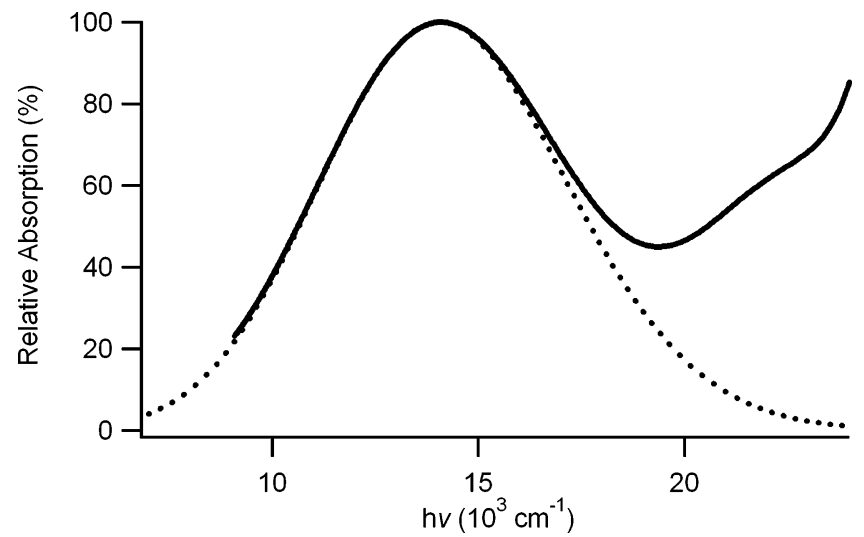

Figure 1. Simulation of the shape of the absorption spectrum of $\mathbf{1}^{+}$ using the modes of Table 1 and $\Gamma=1300 \mathrm{~cm}^{-1}$ (dashed) superimposed on the observed absorption spectrum at $252 \mathrm{~K}$ in acetonitrile.

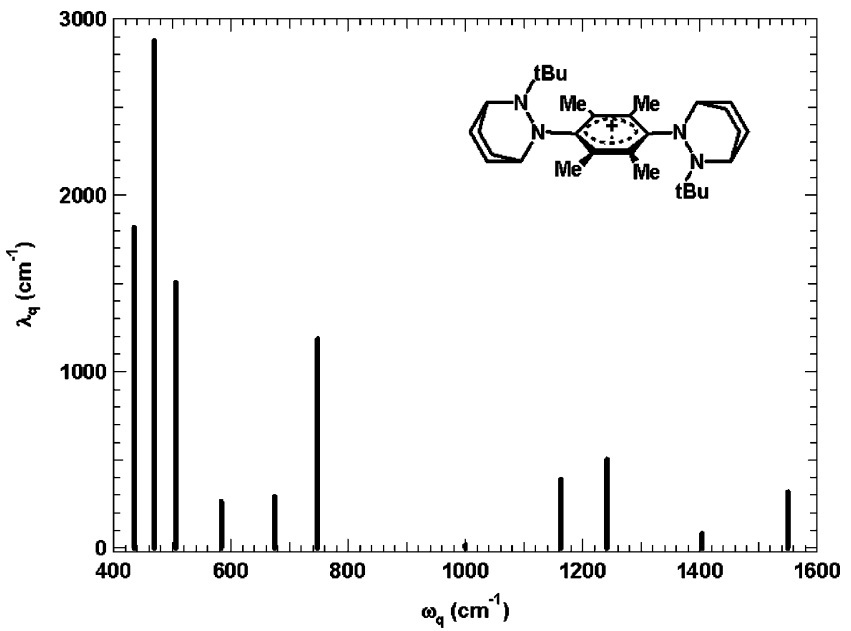

Figure 2. Mode-by-mode contributions to $\lambda_{\mathrm{v}}$ for $\mathrm{Hy}_{2} \mathrm{DU}^{+}$.

time-dependent theory of spectroscopy. The experimental and calculated spectra are shown in Figure 1. For absorption, the time-dependent theory of spectroscopy uses eq 2

$$
I(\omega)=C \omega \int_{-\infty}^{+\infty}\left\{\langle\Phi \mid \Phi(t)\rangle \exp \left(-\Gamma^{2} t^{2}+\frac{i E_{0}}{h} t\right)\right\} \mathrm{d} t
$$

to find the intensity $I$ at a frequency $\omega$. In this model, $\Gamma$ is a phenomenological damping factor that includes relaxation into other modes and the bath, and $E_{0}$ is the origin of the electronic transition. The $\Delta_{\mathrm{q}}$ values are part of $\langle\Phi \mid \Phi(t)\rangle$, the autocorrelation function between the initial ground state wave packet and that wave packet over time as it moves in the excited state after the electronic transition. The modes are uncorrelated with each other, and thus $\langle\Phi \mid \Phi(t)\rangle$ is the product of the contributions of each of the individual vibrational modes. The increments to $\lambda_{\mathrm{v}}$ for each mode are given by $\lambda_{\mathrm{q}}=1 /{ }_{2} \omega_{\mathrm{q}} \Delta_{\mathrm{q}}{ }^{2}$, and these values are shown in Table 1. Figure 2 shows the distribution of the $\lambda_{\mathrm{q}}$ modes, which sum to $\lambda_{\mathrm{v}}=9250 \mathrm{~cm}^{-1}(26.4 \mathrm{kcal} / \mathrm{mol})$, that if equated with $\lambda_{\mathrm{v}}$ would make $\lambda_{\mathrm{s}}\left(\mathrm{CH}_{3} \mathrm{CN}\right)=4850 \mathrm{~cm}^{-1}(14.9$ $\mathrm{kcal} / \mathrm{mol})$ because the total $\lambda$ is $14100 \mathrm{~cm}^{-1}(40.3 \mathrm{kcal} / \mathrm{mol})$. The contributions to $\lambda_{\mathrm{v}}$ are dominated by low-frequency bending and twisting motions: $67 \%$ of $\lambda_{\mathrm{v}}$ arises from modes $\leq 506 \mathrm{~cm}^{-1}$, $73 \%$ from those $\leq 674 \mathrm{~cm}^{-1}$, and $86 \% \leq 748 \mathrm{~cm}^{-1}$.

A completely independent separation of $\lambda_{\mathrm{s}}$ and $\lambda_{\mathrm{v}}$ for $\mathbf{1}^{+}$was achieved by study of shifts in the intervalence band maximum as a function of solvent. ${ }^{51}$ The values obtained in this manner are $\lambda_{\mathrm{v}}=10100 \mathrm{~cm}^{-1}(28.9 \mathrm{kcal} / \mathrm{mol})$ and $\lambda_{\mathrm{s}}\left(\mathrm{CH}_{3} \mathrm{CN}\right)=$ $4000 \mathrm{~cm}^{-1}(11.5 \mathrm{kcal} / \mathrm{mol})$, that is, the present resonance Raman 
study gives $\lambda_{\mathrm{v}}$ as $66 \%$ of the optical transition energy, while the solvent effect on the optical transition energy gave a $\lambda_{v}$ contribution of $72 \%$, which is remarkably good agreement.

The single-mode $\omega_{\mathrm{v}}$ necessary for use with the Golden Rule equation (discussed below) should be the root-mean-square weighted average of the modes involved, which we calculated using $\omega_{\mathrm{v}}=\left[\sum_{\mathrm{q}}\left(\lambda_{\mathrm{v}} \text { sym } / \lambda_{\mathrm{v}}\right)\left(\omega_{\mathrm{v}}\right)^{2}\right]^{1 / 2,52}$ producing $697 \mathrm{~cm}^{-1}$ using the data of Table 1. This value is somewhat smaller than the $800 \mathrm{~cm}^{-1}$ we have used previously for Golden Rule equation rate constant calculations on Hy-centered hydrazine radical cations, ${ }^{15,53}$ which was based upon dynamics calculations on a saturated-bridged bis-bicyclic hydrazine. ${ }^{54}$

Calculation of $\boldsymbol{k}_{\mathrm{ET}}$ from Optically Derived ET Parameters. Classical Marcus ET theory ${ }^{12,13}$ uses a two-state model having parabolic diabatic free energy surfaces that are displaced on the $x$ coordinate, often called the electron-transfer coordinate, that includes both the internal geometry reorganization $\left(\lambda_{\mathrm{v}}\right)$ and the solvent reorganization $\left(\lambda_{\mathrm{s}}\right)$ components of the reorganization energy $\lambda$. The relative sizes of $\lambda$ and the electronic interaction between the diabatic surfaces, $V_{\mathrm{ab}}$, controls the shape of the ground state energy surface. When $V_{\mathrm{ab}}<\lambda / 2$, there is a double minimum on the ground state energy surface with a barrier between them of $\Delta G^{*}=\lambda / 4-V_{\mathrm{ab}}+V_{\mathrm{ab}}^{2} / \lambda$. The expression for the rate constant that Sutin used ${ }^{13}$ is eq 3 ,

$$
k_{\mathrm{et}}=\kappa_{\mathrm{el}} v_{n} \exp \left(-\Delta G^{*} / R T\right)
$$

where $v_{n}=c \omega_{\mathrm{v}}$, the averaged vibrational modes that is the effective nuclear attempt frequency to reach the barrier. $\kappa_{\mathrm{el}}$ represents the electronic tunneling probability. Equation 3 is designed to cover rate constants ranging from the nonadiabatic region, where $\kappa_{\mathrm{el}}=V_{\mathrm{ab}}{ }^{2}\left(\pi / \lambda k_{\mathrm{B}} T\right)^{1 / 2} / \hbar v_{n}$ to the adiabatic region, where $\kappa=1$. In the intermediate region, the prefactor is determined by the Landau-Zener theory developed to allow solution of the two-state model introduced by Landau, Zener, and Steckelberg in 1932 in the electronic coupling region that is chemically significant. ${ }^{55-57}$ Equation 3 works rather well for prediction of $k_{\text {et }}$ as a function of temperature for $\mathbf{1}^{+}$and related compounds using $\lambda$ and $V_{\mathrm{ab}}$ obtained from Hush theory, and agreement with experiment is better when a refractive index correction is included in evaluating $V_{\mathrm{ab}}$ and the diabatic surfaces are allowed to vary from being perfect parabolas by including a quartic term, so that the experimental IV band is properly fit. ${ }^{14,15}$

To incorporate the nuclear quantum effects, the BixonJortner approach abandons the idea of an ET barrier as being important and replaces $\Delta G^{*}$ with Franck-Condon tunneling factors in their rate expressions. Parabolic diabatic energy surfaces are retained, but the $x$ coordinate for these parabolas only includes the low-frequency contributions to $\lambda$ that may be treated classically (usually called $\lambda_{\mathrm{s}}$ and identified as the solvent contribution to $\lambda$ ). The higher frequency components of $\lambda, \lambda_{\mathrm{v}}$, are separated for a quantum mechanical treatment that usually uses a single "averaged" vibrational mode, $\omega_{\mathrm{v}}$, popularized for ET reactions by Jortner and co-workers, ${ }^{58,59}$ and leads to eqs $4 \mathrm{a}-\mathrm{c}$, called the Golden Rule equation by Closs and coworkers. ${ }^{60}$

$$
k_{\mathrm{GR}}=(2 \pi / \nabla)\left|V^{2}\right|(\mathrm{FCWD})
$$

$$
\begin{gathered}
\text { FCWD }=\left(4 \pi \lambda_{\mathrm{s}} k_{\mathrm{b}} T\right)^{-1 / 2} \sum\left(\mathrm{e}^{-S} S^{\mathrm{w}} / \mathrm{w} !\right) \\
\exp \left\{-\left[\left(\lambda_{\mathrm{s}}+\Delta G^{\circ}+\mathrm{w} \omega_{\mathrm{v}}\right)^{2} / 4 \lambda_{\mathrm{s}} k_{\mathrm{b}} \mathrm{T}\right]\right\} \\
S=\lambda_{\mathrm{v}} / \omega_{\mathrm{v}}
\end{gathered}
$$

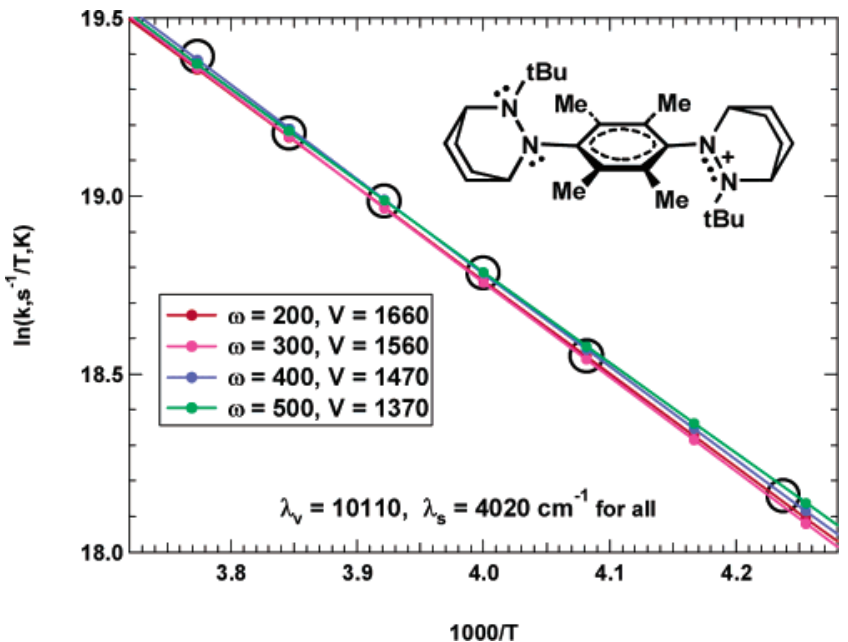

Figure 3. Eyring plots showing best fit of Zhu-Nakamura rate constant calculations to the experimental data for $\mathbf{1}^{+}$in acetonitrile using the room temperature $\lambda$ value.

Although eqs $4 \mathrm{a}-\mathrm{c}$ have been widely used to treat ET rate constants, their use is appropriate for weak electronic coupling cases, that is, where perturbation theory is valid for $V_{\mathrm{ab}}$. As $V_{\mathrm{ab}}$ increases, the evaluation of the ET rate constant remains a challenge because perturbation theory breaks down, which we believe is the reason for eq 4 predicting the wrong temperature dependence for $\mathbf{1}^{+}$and related compounds. ${ }^{14,15,61}$ The classical treatment of eq 3 predicts the rate constant as a function of temperature for $\mathbf{1}^{+}$and related compounds rather accurately, ${ }^{53}$ but it is clear from calculations that this compound cannot be going through a classical transition state for electron-transfer because the electronic coupling would be far too large to be compatible with the observed rate constant. ${ }^{62}$ The appropriate electronic coupling to predict the thermal electron-transfer rate constant is that for the ground state geometry, which is that evaluated from the optical absorption spectrum using Hush theory. This observation is consistent with ET being a tunneling process, which is the assumption upon which eq 4 is based.

Most recently, Zhao et al. ${ }^{63,64}$ have proposed the approach to the ET on the basis of the quantum flux-flux correlation function, the transition-state theory, and the surface hopping technique. The formula is simplified to eqs $5 \mathrm{a}-\mathrm{b}$

$$
k_{\mathrm{et}}=\kappa \exp \left(-\Delta G^{*} / R T\right)
$$

$$
\begin{aligned}
\kappa=\left(2 k_{\mathrm{B}} T / h\right) \sinh \left(\hbar \omega / 2 k_{\mathrm{B}} T\right) \times & \\
& \int_{0}^{\infty} \mathrm{d} E \exp \left[-\left(E-\Delta G^{*}\right) / k_{\mathrm{B}} T\right] P_{\mathrm{ZN}}(E)
\end{aligned}
$$

for an effectively one-dimensional mode system, where $P_{\mathrm{ZN}^{-}}$ (E) represents the Zhu-Nakamura $(\mathrm{ZN})$ nonadiabatic probability $^{3-5}$ at a given energy $E$. Equation 5 represents modified classical Marcus theory that retains an electron-transfer barrier but has a different prefactor that correctly predicts the FranckCondon factor in the nonadiabatic region and that also approaches the Marcus adiabatic ET formula in the high temperature approximation. Because the $\mathrm{ZN}$ formulas that overcome most of the deficiencies of Landau-Zener theory are used in eq $5 \mathrm{~b}$ to obtain the prefactor, it incorporates the nuclear tunneling as well as the combined contribution from electron and nuclear motion. Despite some heuristic corrections to eq 3 , for example, the nuclear tunneling factor is introduced with use of the parabolic approximation, the approximations in eq 3 can be significantly different from the actual solutions. 


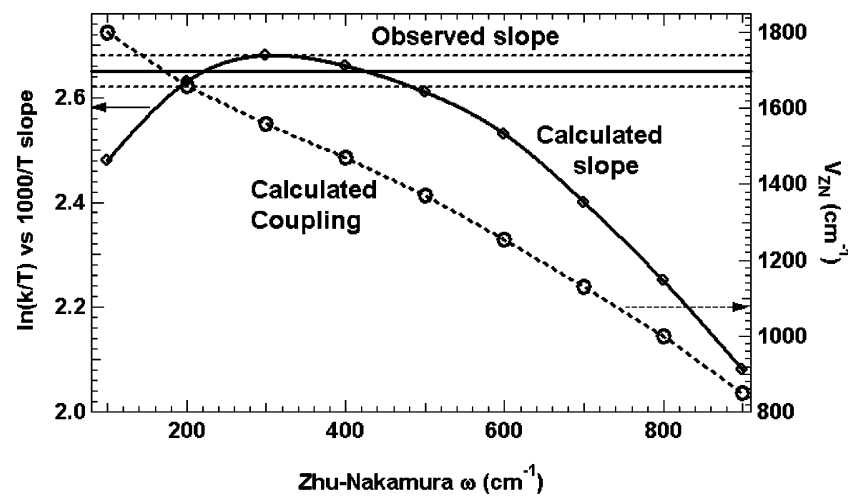

Figure 4. Eyring slopes (left axis, solid line) and electronic coupling (right axis, dashed line) for calculations compared with the experimental value of the slope for $\mathbf{1}^{+}$in acetonitrile (the horizontal dotted lines show 1 standard deviation in this slope).

TABLE 2: Optical Parameters for $1^{+}$as a Function of Temperature $^{a}$

\begin{tabular}{cccccc}
\hline temp, K & $E_{\max }{ }^{a}$ & $E_{\text {quart. }}{ }^{b}$ & quartic coeff $^{b}$ & $\mu_{12}(\mathrm{D})$ & $V_{\text {Hush }}{ }^{b} \mathrm{~cm}^{-1}$ \\
\hline 326 & 14260 & 14095 & 0.18 & 2.205 & 1040 \\
312 & 14210 & 14130 & 0.18 & 2.196 & 1037 \\
298 & 14160 & 14217 & 0.19 & 2.196 & 1038 \\
284 & 14110 & 14217 & 0.20 & 2.203 & 1044 \\
270 & 14050 & 14322 & 0.21 & 2.204 & 1049 \\
255 & 13990 & 14375 & 0.22 & 2.203 & 1050
\end{tabular}

${ }^{a}$ From ref 32. ${ }^{b}$ Redetermined in this work from the spectra reported in ref 32 (see text).

TABLE 3: Electronic Couplings Estimated for $1^{+}$ Considering Temperature Variation of $\lambda$ for the ESR Rate Constants Calculated Using Zhu-Nakamura Formulas

\begin{tabular}{|c|c|c|c|c|c|c|}
\hline$T, \mathrm{~K}$ & $\begin{array}{c}10^{8} k_{\mathrm{ESR}}, \\
\mathrm{s}^{-1}\end{array}$ & $\lambda(T), \mathrm{cm}^{-1}$ & $\begin{array}{c}V_{\mathrm{ZN}} \\
\omega=400\end{array}$ & $\begin{array}{c}V_{\mathrm{ZN}} \\
\omega=500\end{array}$ & $\begin{array}{c}V_{\mathrm{ZN}} \\
\omega=600\end{array}$ & $\begin{array}{c}V_{\mathrm{ZN}} \\
\omega=700\end{array}$ \\
\hline 265 & 2.64 & 14227 & 1480 & 1350 & 1197 & 1017 \\
\hline 260 & 2.13 & & 1480 & 1348 & 1190 & 1004 \\
\hline 255 & 1.76 & & 1485 & 1350 & 1188 & 996 \\
\hline 250 & 1.44 & 14390 & 1489 & 1352 & 1188 & 988 \\
\hline 245 & 1.14 & & 14 & 1352 & 1178 & 945 \\
\hline 236 & 0.77 & 14445 & 1498 & 1353 & 1174 & 953 \\
\hline
\end{tabular}

Treatment of the ESR Rate Constants Using ZhuNakamura Formulas. The experimental rate constant data for $\mathbf{1}^{+}$consists of six rate constants measured by ESR between 236 and $265 \mathrm{~K} .{ }^{15}$ Figure 3 compares Eyring plots of the observed ESR rate constants with $\mathrm{Zhu}-\mathrm{Nakamura}$ (eq 5) calculations where pairs of $\omega$ and $V$ values that produce Eyring plots within experimental error of the ESR rate constants (shown as the black circles). These calculations were done using the partitioning of the room temperature IV band maximum in acetonitrile, taken as $\lambda$, into $\lambda_{\mathrm{v}}=10110 \mathrm{~cm}^{-1}$ and $\lambda_{\mathrm{s}}=4020 \mathrm{~cm}^{-1}$ that arose from how $\lambda$ changes with solvent. ${ }^{51}$ However, other calculations showed that the results were indistinguishable if $\lambda$ was not broken into vibrational and solvent components but taken as a single $14130 \mathrm{~cm}^{-1}$ quantity (see Supporting Information). This result is very different from that obtained using Bixon-Jortner theory to calculate rate constants, where $S=\lambda_{\mathrm{v}} / \omega_{\mathrm{v}}$ is a parameter of fundamental importance, so the partitioning of $\lambda$ is crucial. Calculations varying $\omega$ from 100 to $800 \mathrm{~cm}^{-1}$ values, also at $\lambda=14130 \mathrm{~cm}^{-1}$ are shown in Figure 4. The $V$ value for best fit to $k_{\mathrm{ESR}}$ at $250 \mathrm{~K}$, near the center of the range of temperatures, where accuracy in determining $k_{\mathrm{ESR}}$ is best, is shown as the blue circles and line (plotted on the right axis). The red circles and line show the calculated Eyring slope in the 236-265 K temperature range are plotted on the left axis. It is seen that Eyring slopes within 1 standard deviation of the observed slope

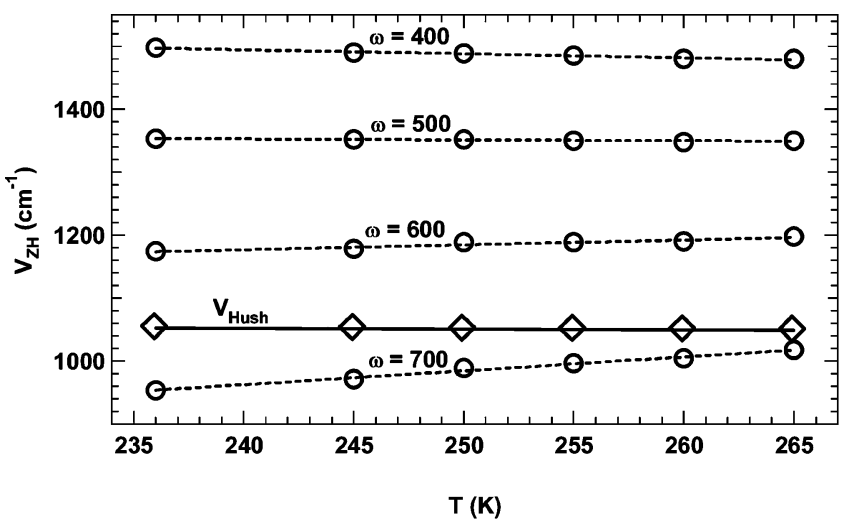

Figure 5. Circles: Plot of $V_{\mathrm{ZH}}$ as a function of temperature and $\omega$ obtained for the $k_{\mathrm{ESR}}, \lambda$ pairs (Table 5), chosen for best fit to $k_{\mathrm{ESR}}$ at $250 \mathrm{~K}$. Diamonds: Plot of optically derived $V_{\text {Hush }}($ Table 2 ) as a function of temperature.

are obtained for $\omega=200-500 \mathrm{~cm}^{-1}$ and that the corresponding electronic coupling drops approximately linearly, by about $1 \mathrm{~cm}^{-1}$ in $V_{\mathrm{ZN}}$ per $\mathrm{cm}^{-1}$ change in $\omega$ over this range, from 1660 to $1370 \mathrm{~cm}^{-1}$. However the series of calculations shown in Figure 4 do not take into account the fact that both $\lambda$ and the optical $V$ value, $V_{\text {Hush }}$, are experimentally slightly temperature sensitive, ${ }^{53}$ so we will next consider the effect of allowing these quantities to vary. Table 2 shows variable temperature optical measurements, with recalculated $V_{\text {Hush }}$ (evaluated using the dication triplet ESR-derived electron-transfer distance on the adiabatic surfaces, $d_{12}=5.63 \AA,{ }^{15}$ corresponding to the ET distance $d_{\mathrm{ab}}=5.71 \AA$ ), employing a refractive index correction ${ }^{65}$ and integration of the IV band to determine $\mu_{12}$, as described recently. ${ }^{66} V_{\text {Hush }}$ calculated in this manner decreases about 0.34 $\mathrm{cm}^{-1} / \mathrm{K}$ as the temperature in increased. The direction of the change seems reasonable because increasing temperature should slightly increase the average amount of twist about the $\mathrm{C}-\mathrm{N}$ bonds connecting the hydrazine units to the bridge, which will decrease the electronic coupling. Instead of using the band maxium as $\lambda$, as was done previously, ${ }^{32}$ the IV band was fit more realistically, using a quartic-enhanced IV band ${ }^{14}$ along with higher energy Gaussians as needed to fit the observed spectrum, which upon analyzing substituted naphthalenes that have even more band overlap, ${ }^{66}$ we realized will produce more realistic temperature variation of the IV band. The $E_{\text {quart }}$ values of Table 2 were used to establish a line for $\lambda(T)$, which was used to estimate the $\lambda(T)$ values at the temperatures of the ESR data.

Table 3 shows the ESR rate constants as a function of temperature, extrapolated $\lambda(T)$ values, and Zhu-Nakamuraderived $V_{\mathrm{ZH}}$ values as a function of $\omega$ that best fit the rate constant, $\lambda$ pairs at $250 \mathrm{~K}$. As may be seen in the plot of these data in Figure 5, the slopes of the $V_{\mathrm{ZH}}$ values for best fit with the ESR rate constants at $250 \mathrm{~K}$ depend upon $\omega: V_{\mathrm{ZN}}$ decreases $-0.64 \mathrm{~cm}^{-1} / \mathrm{K}$ at $\omega=400 \mathrm{~cm}^{-1}$ and $-0.15 \mathrm{~cm}^{-1} / \mathrm{K}$ at $\omega=$ 500 , but increases at higher $\omega$ values, $+0.77 \mathrm{~cm}^{-1} / \mathrm{K}$ at $\omega=$ $600 \mathrm{~cm}^{-1}$ and $+2.19 \mathrm{~cm}^{-1} / \mathrm{K}$ at $\omega=700 \mathrm{~cm}^{-1}$. The optically derived $V_{\text {Hush }}$ decreases slightly as temperature increases, slope $-0.13 \mathrm{~cm}^{-1} / \mathrm{K}$. This is reasonable because electronic coupling depends upon overlap of the charge-bearing units with the bridge, making $V$ about proportional to $\cos \phi$ at each of the $\mathrm{CN}$ connecting bonds, and we expect the average value of $\phi$ to increase slightly as the temperature increases. Although the temperature sensitivity of $V_{\mathrm{ZN}}$ is closer to that for $V_{\text {Hush }}$ at $\omega=$ $500 \mathrm{~cm}^{-1}$, the size of $V_{\mathrm{ZN}}$ is closer to $V_{\text {Hush }}$ near about $\omega=$ $660-680 \mathrm{~cm}^{-1}$, depending upon temperature. It is not obvious how sensitve $\omega$ should be to temperature. 
However, a smaller $\omega$ than the resonance Raman $\omega_{\mathrm{v}}$ fits the ESR and optical data better. This is expected because a single $\omega$ eq 5 calculation must include the low-frequency solvent modes as well as higher frequency internal vibration modes. Newton and Sutin have discussed the effective frequency arising from intramolecular and solvent modes. ${ }^{67,68}$ Following them, the effective frequency used in eq 5 is written as eq 6

$$
\omega_{\text {eff }}^{2}=\left(\omega_{\mathrm{v}}^{2} \lambda_{\mathrm{v}}+\omega_{\mathrm{s}}^{2} \lambda_{\mathrm{s}}\right) / \lambda
$$

where $\omega_{\mathrm{s}}$ is the solvent rotational frequency. Dmitry Matyushov (Arizona State) ${ }^{69}$ derived an expression using a quasi-classical approximation that gives a somewhat different expression for the effective $\omega$ value, as shown in eq 7

$$
\omega_{\mathrm{eff}}^{\prime} \approx\left(\Sigma_{\mathrm{q}} \lambda(q) \omega(q)+\lambda_{\mathrm{s}} / \tau_{\mathrm{L}}\right) / \lambda
$$

These expressions explicitly show that $\omega$ is always smaller than $\omega_{\mathrm{v}}$. Using recent dielectric data for acetonitrile $\mathrm{e}^{70}$ as summarized by Matyushov ${ }^{71}$ produces $\tau_{\mathrm{L}}{ }^{-1}=185 \mathrm{~cm}^{-1}$. Using this value as $\omega_{\mathrm{s}}$ in (6) with the resonance Raman $\lambda_{\mathrm{v}}$ of $9248 \mathrm{~cm}^{-1}$ gives $\omega_{\text {eff }}=574 \mathrm{~cm}^{-1}$, while (7) produces a lower value, $\omega^{\prime}{ }_{\text {eff }}=$ $414 \mathrm{~cm}^{-1}$. Thus the Newton-Sutin estimate of $\omega$ (eq 6) is consistent with a $V_{\mathrm{ZN}}$ at $250 \mathrm{~K}$ of about $1230 \mathrm{~cm}^{-1}$, while the Matyushov estimate with $V_{\mathrm{ZN}}$ of about $1470 \mathrm{~cm}^{-1}$, both of which are larger than the Hush estimate derived from the optical spectra of about $1050 \mathrm{~cm}^{-1}$. Nevertheless, we consider these results rather good agreement for the quite independent estimations of the effective $\omega$ using the temperature variation of the ESR rate constant as analyzed by ZN theory and the resonance Raman spectrum. Thus Marcus-Hush analysis of the optical data to evaluate $\lambda$ and $V_{\text {Hush }}$ produces a larger value $\left(\mathrm{ca} .670 \mathrm{~cm}^{-1}\right.$ ) than the resonance Raman-derived fractionation of $\lambda_{\mathrm{v}}$ into its mode-by-mode components (414 or $575 \mathrm{~cm}^{-1}$, depending on whether eq 6 or 7 is used to estimate the effective $\omega$ value.

\section{Summary}

A resonance Raman study revealed 11 modes excited by irradiation into the intervalence band of $\mathbf{1}^{+}$. They range from 435 to $1550 \mathrm{~cm}^{-1}$, and their incremental contributions sum to $\lambda_{\mathrm{v}}^{\text {sym }}=9250 \mathrm{~cm}^{-1}$. Low-frequency bending and twisting motions predominate in causing this vibrational reorganization energy: $67 \%$ of $\lambda_{\mathrm{v}}$ sym arises from modes $\leq 506 \mathrm{~cm}^{-1}$ and $86 \%$ from those $\leq 748 \mathrm{~cm}^{-1}$. The value of $\omega_{\mathrm{v}}$ obtained from the resonance Raman data is $697 \mathrm{~cm}^{-1}$, which produces a predicted single mode effective $\omega$ value of 574 and $414 \mathrm{~cm}^{-1}$ using eqs 6 and 7, respectively. The Zhu-Nakamura formulas have been used obtaining $\omega, V$ combinations that are consistent with the experimental temperature dependence of the ESR-derived electron-transfer rate constant and optical $\lambda$ value. In contrast to using Bixon-Jortner theory, separation of $\lambda$ into its $\lambda_{\mathrm{s}}$ and $\lambda_{\mathrm{v}}$ components does not significantly affect the $\omega, V$ pairs that fit a given rate constant. Using the Zhu-Nakamura preexponential factor of eq 5 gives good agreement for the ESR rate constants using an $\omega$ value that is close to those estimated from the resonance Raman spectroscopic data but requiring a slightly higher electronic coupling than $\mathrm{V}_{\text {Hush }}$.

Acknowledgment. This work was made possible by grants from the National Science Foundation, CHE-0240197 (S.F.N.) and CHE-0507929 (J.I.Z.), and NSFC-20473080 (Y.Z.).

Supporting Information Available: Absolute and normalized intensity data for the resonance Raman of $\mathbf{1}^{+}$, additional Eyring plot comparisons of experimental and calculated rate constant data, and the data plotted in Figure 4. This material is available free of charge via the Internet at http://pubs.acs.org.

\section{References and Notes} 422.

(1) Robin, M. B.; Day, P. Adv. Inorg. Radiochem. 1967, 10, 247-

(2) Creutz, C.; Taube, H. J. Am. Chem. Soc. 1969, 91, 3988-9.

(3) Creutz, C. Prog. Inorg. Chem. 1983, 30, 1-73.

(4) Crutchley, R. J. Adv. Inorg. Chem. 1994, 41, 273-325.

(5) Hush, N. S. Prog. Inorg. Chem. 1967, 8, 391-444.

(6) Hush, N. S. Coord. Chem. Rev. 1985, 64, 135-157.

(7) For the early history of radical ion studies, see: Roth, H. D. Tetrahedron 1986, 42, 6097-6100.

(8) We believe that Cowan and co-workers first pointed out an allorganic Class III intervalence system, tetrathiofulvalene radical cation: Cowan, D. O.; LeVanda, C.; Park, J.; Kaufman, F. Acc. Chem. Res. 1973, $6,1-7$.

(9) Nelsen, S. F.; Chang, H.; Wolff, J. J.; Adamus, J. J. Am. Chem. Soc. 1993, 115, 12276-12289.

(10) Nelsen, S. F.; Ismagilov, R. F.; Powell, D. R. J. Am. Chem. Soc. 1996, 118, 6313-6314.

(11) For a recent review see: Nelsen, S. F. Adv. Phys. Org. Chem. 2006, $41,183-215$.

(12) Marcus, R. A. J. Chem. Phys. 1956, 24, 966-978.

(13) Sutin, N. Prog. Inorg. Chem. 1983, 30, 441-499.

(14) Nelsen, S. F.; Ismagilov, R. F.; Trieber, D. A., II Science 1997, 278, 846-849.

(15) Nelsen, S. F.; Ismagilov, R. F.; Powell, D. R. J. Am. Chem. Soc. 1997, 119, 10213-10222.

(16) Yang, Y. Y. and Zink, J. I. J. Am. Chem. Soc. 1984, 106, 1500.

(17) Zink, J. I. Coord. Chem. Rev. 1985, 64, 93.

(18) (a) Doorn, S. K.; Hupp, J. T. J. Am. Chem. Soc. 1989, 111, 11421144. (b) Doorn, S. K.; Hupp, J. T. J. Am. Chem. Soc. 1989, 111, 47044712 .

(19) Henary, M.; Zink, J. I. J. Am. Chem. Soc. 1989, 111, 7407.

(20) Shin, K. S.; Clark, R. J. H.; Zink, J. I. J. Am. Chem. Soc. 1990, 112,3754 .

(21) Shin, K. S.; Clark, R. J. H.; Zink, J. I. J. Am. Chem. Soc. 1990, 112,7148 .

(22) Kim Shin, K.-S.; Zink, J. I. J. Am. Chem. Soc. 1990, 112, 7148.

(23) Doorn, S. K.; Hupp, J. T.; Porterfield, D. R.; Campion, A.; Chase, D. B. J. Am. Chem. Soc. 1990, 112, 4999-5002.

(24) Doorn, S. K.; Blackbourn, R. L.; Johnson, C. S.; Hupp, J. T. Electrochim. Acta 1991, 36, 1775-1785.

(25) Blackbourn, R. L.; Johnson, C. S.; Hupp, J. T. J. Am. Chem. Soc. 1991, 113, 1060-1062

(26) (a) Petrov, V.; Hupp, J. T.; Mottley, C.; Mann, L. C. J. Am. Chem. Soc. 1994, 116, 2171. (b) Lu, H.; Petrov, V.; Hupp, J. T. Chem. Phys. Lett. 1995, 235, 521-527.

(27) Wootton, J. L.; Zink, J. I. J. Phys. Chem. 1995, 99, 7251.

(28) Henary, M.; Wootton, J. L.; Khan, S. I.; Zink, J. I. Inorg. Chem. 1997, 36, 796.

(29) Hanna, S. D.; Zink, J. I. Inorg. Chem. 1996, 35, 297

(30) Zink, J. I. Coord. Chem. Rev. 2001, 211, 69.

(31) Blackbourn, R. L.; Johnson, C. S.; Hupp, J. T.; Bryant, M. A.; Sobocinski, R. L.; Pemberton, J. E. J. Phys. Chem. 1991, 95, 10535-10537. (32) Meyers, A. B. Chem. Phys. 1994, 180, 215.

(33) Godbout, J. T.; Pietrzykowski, M. D.; Gould, I. R.; Goodman, J. T.; Kelly, A. M. J. Phys. Chem. A 1999, 103, 3876-3883.

(34) Kelly, A. M. J. Phys. Chem. A 1999, 103, 6891-6903.

(35) Meyers, A. B. Chem. Rev. 1996, 96, 911-926.

(36) Doorn, S. K.; Blackbourn, R. L.; Johnson, C. S.; Hupp, J. T. Electrochim. Acta 1991, 36, 1775-1785.

(37) Blackbourn, R. L.; Johnson, C. S.; Hupp, J. T. J. Am. Chem. Soc. 1991, 113, 1060-1062

(38) Bailey, S. E.; Zink, J. I.; Nelsen, S. F. J. Am. Chem. Soc. 2003, $125,5939-5947$.

(39) Szeghalmi, A. V.; Erdmann, M.; Engel, V.; Schmidt, M.; Amthor, S.; Kriegisch, V.; Nöll, G.; Stahl, R.; Lambert, C.; Leusser, D.; Stalke, D.; Zabel, M.; Popp, J. J. Am. Chem. Soc. 2004, 126, 7834-7845.

(40) Lockard, J. V.; Zink, J. I.; Trieber, D. A., II; Konradsson, A. E.; Weaver, M. N.; Nelsen, S. F. J. Phys. Chem. A 2005, 109, 1205-1215.

(41) Lockard, J. V.; Valverde, G.; Neuhauser, D.; Zink, J. I.; Luo, Y.; Weaver, M. N.; Nelsen, S. F. J. Phys. Chem. A 2006, 110, 57-66.

(42) Lee, S.-Y.; Heller, E. J. J. Chem. Phys. 1979, 71, 4777.

(43) Heller, E. J. Acc. Chem. Res. 1981, 14, 368-375.

(44) Heller, E. J.; Sundberg, R. L.; Tannor, D. J. Phys. Chem. 1982, $86,1822-1833$

(45) Zink, J. I.; Shin, K.-S. K. In Advances in Photochemistry; Wiley: New York, 1991; Vol. 16, p 119.

(46) Shin, K.-S. K.; Zink, J. I. Inorg. Chem. 1989, 28, 4358.

(47) Myers Kelley, A. J. Phys. Chem. A 1999, 103, 6891. 
(48) Myers, A. B. Chem. Rev. 1996, 96, 911

(49) Myers, A. B. Acc. Chem. Res. 1997, 30, 519

(50) Myers, A. B. In Laser Techniques in Chemistry; Wiley: New York, 1995; Vol. 23, p 325.

(51) Nelsen, S. F.; Trieber, D. A., II.; Ismagilov, R. F.; Teki, Y. J. Am Chem. Soc. 2001, 123, 5684 .

(52) Equation 45 of ref 13.

(53) Nelsen, S. F.; Ismagilov, R. F.; Gentile, K. E.; Powell, D. R. J. Am. Chem. Soc. 1999, 121, 7108-7114.

(54) Nelsen, S. F. J. Am. Chem. Soc. 1996, 118, 2047-2058.

(55) Zhu, C.; Nakamura, H. J. Chem. Phys. 1994, 101, 10630-10647.

(56) Zhu, C.; Nakamura, H. J. Chem. Phys. 1995, 102, 7448-7462.

(57) Zhu, C.; Teranishi, Y.; Nakamura, H. Adv. Chem. Phys. 2001, 117, 127-233.

(58) Ulstrup, J.; Jortner, J. J. Chem. Phys. 1975, 63, 4358-4368.

(59) Bixon, M.; Jorner, J. Adv. Chem. Phys. 1999, 106, 35-202.

(60) (a) Closs, G. L.; Miller, J. R. Science 1988, 240, 440-448. (b) Liang, N.; Miller, J. R.; Closs, G. L. J. Am. Chem. Soc. 1989, 111, 87408741. (c) Liang, N.; Miller, J. R.; Closs, G. L. J. Am. Chem. Soc. 1990, $112,5353-5354$

(61) A more complicated, double sum form of eq 4 was actually used for these intervalence compounds, ${ }^{14,15}$ which is necessary because $\Delta G^{\circ}=$ 0 and the "forward" rate is the same as the "back" rate. A still more complex, Bessel function form of eq 4 has been proposed to correct for $\omega_{\mathrm{v}}$ being greater than $2 k T$ (ref 59, eq 5.28) but to our knowledge is seldom used by experimentalists. We do not think its use would improve agreement with our experimental data significantly. The principal problem with eq 4, it seems to us, is that $S$ is not an important parameter for this compound.

(62) Blomgren, F.; Larsson, S.; Nelsen, S. F. J. Comput. Chem. 2001, 22,655 .

(63) Zhao, Y.; Mil'nikov, G.; Nakamura, H. J. Chem. Phys. 2004, 121, $8854-8860$

(64) Zhao, Y.; Nakamura, H. J. Theor. Comput. Chem. 2006, 5, 299306.

(65) We note that not including the refractive index correction (which Hush never used) increases what we call $V_{\text {Hush }}$ by about $100 \mathrm{~cm}^{-1}$ for these data, which it will be noted below would improve agreement with the ZhuNakamura calculations.

(66) Nelsen, S. F.; Konradsson, A. E.; Teki, Y. J. Am. Chem. Soc. 2006 $128,2902-2910$

(67) Newton, M. D.; Sutin, N. Annu. Rev. Phys. Chem. 1984, 35, 437480.

(68) Sutin, N. Prog. Inorg. Chem. 1983, 30, 441-499.

(69) Matyushov, Dmitry V. Private communications, August 2006.

(70) Asaki, M. L. T.; Redondo, A.; Zawodzinski, T. A.; Taylor, A. J. J. Chem. Phys. 2002, 116, 10377-10385.

(71) Matushov, D. V. J. Chem. Phys. 2005, 122, 044502.1-11. 